\title{
Extracorporeal life support for management of refractory cardiac or respiratory failure: initial experience in a tertiary centre
}

\author{
Adriano Peris', Giovanni Cianchi', Simona Biondi2, Manuela Bonizzoli', Andrea Pasquini', Massimo Bonacchi3, \\ Marco Ciapetti ${ }^{1}$, Giovanni Zagli*1 ${ }^{*}$ Simona Bacci ${ }^{1}$, Chiara Lazzeri ${ }^{4}$, Pasquale Bernardo ${ }^{4}$, Erminia Mascitelli3 , Guido Sani ${ }^{3}$ \\ and Gian Franco Gensini4
}

\begin{abstract}
Introduction: Extracorporeal Life Support (ECLS) and extracorporeal membrane oxygenation (ECMO) have been indicated as treatment for acute respiratory and/or cardiac failure. Here we describe our first year experience of inhospital ECLS activity, the operative algorithm and the protocol for centralization of adult patients from district hospitals.

Methods: At a tertiary referral trauma center (Careggi Teaching Hospital, Florence, Italy), an ECLS program was developed from 2008 by the Emergency Department and Heart and Vessel Department ICUs. The ECLS team consists of an intensivist, a cardiac surgeon, a cardiologist and a perfusionist, all trained in ECLS technique. ECMO support was applied in case of severe acute respiratory distress syndrome (ARDS) not responsive to conventional treatments. The use of veno-arterial (V-A) ECLS for cardiac support was reserved for cases of cardiac shock refractory to standard treatment and cardiac arrests not responding to conventional resuscitation.

Results: A total of 21 patients were treated with ECLS during the first year of activity. Among them, 13 received ECMO for ARDS (5 H1N1-virus related), with a $62 \%$ survival. In one case of post-traumatic ARDS, V-A ECLS support permitted multiple organ donation after cerebral death was confirmed. Patients treated with V-A ECLS due to cardiogenic shock $(\mathrm{N}=4)$ had a survival rate of 50\%. No patients on V-A ECLS support after cardiac arrest survived $(\mathrm{N}=4)$.

Conclusions: In our centre, an ECLS Service was instituted over a relatively limited period of time. A strict collaboration between different specialists can be regarded as a key feature to efficiently implement the process.
\end{abstract}

\section{Introduction}

Extracorporeal circulation support techniques have been proposed either for treatment of cardiac and/or pulmonary failure refractory to conventional treatments in adult patients. The first device, which assured blood extracorporeal oxygenation and perfusion of isolated organs, was developed by von Frey and Gruber in 1885 [1]. The first heart-lung machine was projected by Gibbon in 1937 in order to allow open-heart surgical operations [2]. Over the years, extracorporeal circulation circuit has been improved and the technique optimized,

* Correspondence: giovanni.zagli@unifi.it

${ }^{1}$ Anaesthesia and Intensive Care Unit of Emergency Department, Careggi Teaching Hospital, Florence, Italy

Full list of author information is available at the end of the article and it is now available for clinical practice. From a general point of view, two methods of support are outlined: venovenous extracorporeal oxygenation, commonly known as ECMO, Extracorporeal Membrane Oxygenation, for respiratory function substitution and extracorporeal life support technique (ECLS) with a veno-arterial circulation for both oxygenation and hemodynamic assistance. The major indications for ECMO, in adult patients, are severe acute respiratory distress syndrome (ARDS) refractory to conventional treatments [3,4], and, in selected cases, post-traumatic respiratory failure, severe asthma $[5,6]$, and chronic lung disease waiting for lung transplantation $[7,8]$.

The indications for ECLS and cardiac support are cardiac failure due to any cause, and cardiac arrest not responsive 
to Advanced Life Support manoeuvres. In the first case, the in-hospital mortality rate is still high (between 33\% and $38 \%$ ) and ECLS represents a rescue-therapy useful for refractory patients [9]. In case of in-hospital cardiac arrest, when ECLS was used after ten minutes of unsuccessful cardiopulmonary resuscitation, an increase in survival rate at ICU discharge, at 30-day and at 1-year survival was reported [10].

At a tertiary referral trauma center (Careggi Teaching Hospital, Florence, Italy) an ECLS program was developed beginning April 2008 by the Intensive Care Unit of Emergency Department in association with the Intensive Cardiac Coronary Unit of Heart and Vessel Department. Here we describe our experience in implementing a multidisciplinary ECLS team for cardiac and respiratory failure. In addition to reporting our clinical experience, we present the algorithm for ECLS activation for in-hospital cardiac arrest and the experience of a national referral center for treatment of $\mathrm{H} 1 \mathrm{~N} 1$ influenza related respiratory failure.

\section{Methods \\ ECLS Team}

The ECLS team consists of an intensivist, a cardiac surgeon, a cardiologist and a perfusionist, all trained on ECLS technique and management. According to our activation protocol, ECLS team can be summoned within one hour, with 24 hour coverage.

In most cases, the intensivist primes the process on the basis of clinical and radiological findings and activates the full ECLS team. The cardiologist's main task is to evaluate cardiac function in the pre-ECLS phase and guides the correct positioning of ECLS cannulas by transesophageal ultrasonography. Furthermore, the cardiologist is directly involved in selecting patients with cardiac failure suitable for ECLS treatment. The cardiac surgeon, in addition to actively participating to the clinical decision making process, is responsible for selecting and inserting the cannulas and starting the extracorporeal circulation, with the assistance of the perfusionist.

In case of an ECLS run, irrespectively of the unit where the patient was admitted (General or Cardiac ICU), all the professionals of the team were available for consultation and performed at least one daily evaluation.

This study, supported by institutional funds only, followed the principles of the Helsinki declaration and was approved by the Internal Review Board. Informed consent for data publication was obtained.

\section{ECLS for respiratory failure}

Veno-venous ECLS treatment (ECMO) was applied in case of severe ARDS not responsive to conventional treatments, but potentially reversible. Conditions of severe hypoxia or hypercapnia, where the limits of a pro- tective ventilation strategy could not be maintained (tidal volume less than $6 \mathrm{~mL} / \mathrm{Kg}$ of predicted body weight and plateau pressure less than $30 \mathrm{cmH}_{2} \mathrm{O}$ ), were the indications for starting extracorporeal circulation [11]. The Careggi Teaching Hospital had started a collaboration with the ICUs of 12 district hospitals in Tuscany in a pilot project for centralization of acute lung injury/ARDS patients who require (or may require) ECLS treatment. In 2008 and spring 2009, preliminary meetings were organized to inform the peripheral hospitals' ICU staff and Administrations about the availability of the new ECLS program. During the H1N1 influenza A pandemic, the knowledge of ECMO treatment rapidly spread among the medical community and the Regional Ministry of Health issued indications to transfer all patients affected by severe respiratory failure related to influenza to Careggi Hospital. In Appendix 1 is reported the set of parameters that were adopted to quickly detect patients suitable for extracorporeal treatment in the peripheral hospitals. Patients deemed suitable for ECMO treatment were evaluated on site by the ECMO team. Depending on clinical condition, the transfer was performed on conventional ventilation or, alternatively, ECLS treatment was initiated in the peripheral hospital and maintained during transportation [12].

We preferentially adopted a high flow technique (5-6 litres per minute of blood flow), to maximize the opportunity of providing protective ventilation, aiming to achieve a plateau pressure below $28 \mathrm{~cm} \mathrm{H}_{2} \mathrm{O}$ and PEEP 2 $\mathrm{cmH}_{2} \mathrm{O}$ above the lower inflection point of the quasistatic pressure volume curve, regardless the delivered tidal volume (in any case less than $6 \mathrm{ml} / \mathrm{kg}$ ). Controlled respiratory frequency was reduced to $4-10 / \mathrm{min}$ to maintain normocapnia. Inspired oxygen fraction was reduced to 0.5 or lower, whenever possible. A recruitment manoeuvre was performed at least once a day, and ventilation with an intermittent high pressure breath ("sigh") was adopted to improve lung aeration [13]. During ECMO, nitric oxide administration [14], vasoactive support, and prone positioning were maintained or initiated according to clinical conditions.

\section{ECLS for hemodynamic support}

The use of ECLS for cardiac support was reserved for cases of cardiac shock refractory to standard treatments and cardiac arrests not responding to conventional resuscitation. According to our internal protocol, ECLS was adopted also as a bridge to implantation of Left Ventricular Assist Device or to heart transplantation [15].

ECLS was employed in cases of in-hospital cardiac arrest when the patient was considered to have a good chance of recovery both for clinical conditions and for the timing of resuscitation. An age limit of seventy years, severe irreversible brain damage, terminal malignancy, pre-signed 
"do not attempt resuscitation" orders and contraindications to prolonged systemic heparin infusion were the only strict exclusion criteria taken into account. In case of cardiac arrest, hypothermia was rapidly initiated and was maintained for 24 hours at a temperature between 32 $34^{\circ} \mathrm{C}[16]$.

Veno-arterial (V-A) ECLS treatment was considered contraindicated, when a severe aortic incompetence, aortic dissection or ventricular thrombosis was detected by echocardiography.

\section{Equipment}

The ECLS circuit consisted of a Rotaflow Maquet Centrifugal Pump (Maquet, Rastatt, Germany) and a hollow fiber membrane oxygenator (Quadrox-D Oxygenator, Maquet, Rastatt, Germany), connected with biocoated tubes. In the V-A circuit, blood was drained through femoral vein and reinfused into aorta through femoral artery. For V-V ECLS two types of cannulas were used. At the beginning, Raumedic cannulas ranging from 21 to 28 french (Raumedic AG, Germany) were employed with femoral and jugular vein cannulation. Since July 2009, Avalon Elite ${ }^{\mathrm{m}} \mathrm{Bi}$-Caval Dual Lumen Catheters have become available. These specially designed dual lumen cannulas, inserted in the right internal jugular vein, permit both drainage and reinfusion of blood. In V-A ECLS, the distal perfusion of the limb could be jeopardized by the relatively large bore inflow cannula, inserted in the femoral artery at the groin: to prevent leg ischemia, we usually inserted a small shunt cannula (14 french) in the femoral artery, distally to the ECLS cannula. Heparin therapy was titrated by bedside measurement of activated partial thromboplastin time (aPTT) with Hemochron (Hemochron Jr. Sign. plus, ITC Europe, Milan, IT) every two hours.

Numerical data were summarised as median and interquartile range.

\section{Results}

A total of 21 patients were treated with ECLS during the first one year of activity (April 2008 - December 2009). Among them, 13 were treated with ECMO for respiratory failure (Table 1), and 8 were treated with V-A ECLS due to cardiac arrest (Table 2) and cardiogenic shock (Table 3 ). The most frequent complication observed was local bleeding from the insertion points of the cannulae, central line access site and tracheostomy (36\%). In one case, oxygenator failure occurred due to clots formation; in this occasion a rapid increase of D-Dimers was observed, followed by a worsening of oxygenation and decarboxylation performance of the artificial lung. Circuit change was promptly carried out with no further complications. In one case of V-A ECLS, major bleeding occurred at site of cannulae insertion several days after successful wean- ing, requiring multiple transfusions. At surgical inspection a femoral artery wall lesion was found and required prosthetic repair.

Five patients received renal replacement therapy (continuous veno-venous hemofiltration, $\mathrm{CVVH}$ ). The CVVH was connected in-line to the extracorporeal circuit with the withdrawal line before oxygenator and return line after the oxygenator. Renal function recovered in all cases, and both ECLS and CVVH run was uneventful on this configuration.

During extracorporeal support, invasive procedures were carried out without any immediate complications. Among these, four bedside percutaneous tracheotomies (Ciaglia technique) were performed, and two narrow bore pleural catheters were inserted under ultrasound guidance for massive pleural effusions. Autopsy was performed in all non surviving patients and no lesion of vessels due to the presence of cannulae was observed.

\section{ECMO for respiratory failure}

A total of 13 patients were treated with ECMO for ARDS: six patients were affected by bacterial pneumonia, five patients had H1N1-related ARDS (two with Legionella Pneumophila superinfection), and 2 patients presented trauma-related respiratory failure. Data of each patient are represented in Table 1 . Median age was 59 years (IQR 44-65), with a prevalence of male sex (85\%). Median ICU length of stay was 17 days (IQR 13-20). Eight out of 13 patients were successfully weaned from ECMO and discharged from ICU (overall survival rate of $62 \%$ ). All H1N1 patients were discharged from ICU and from hospital.

The median duration of ECMO was 235 hours (IQR 151269), with a difference between survivors (221 hours) and non survivors (257 hours). We considered time from verification of ECMO criteria to extracorporeal support start as an efficiency parameter ("time to ECMO"), and it was 6 hours (IQR 4-9).

From October 2009, when our ECMO Service became the referral centre of Central Italy for H1N1-induced ARDS, extracorporeal support was initiated in the peripheral hospital in 3 cases. Inter-hospital transport was safely performed on extracorporeal support and all patients were discharged alive from ICU.

One young patient (19 years) died due to severe traumatic brain injury. In this patient, ECMO was maintained in the first 12 hours without systemic heparin infusion and no complications occurred during extracorporeal treatment. After cerebral death confirmation, multiple organ donation was accomplished. One patient (a 64 year-old woman) died due to subarachnoidal hemorrhage, although coagulation parameters were normal. 
Table 1: Patients treated with ECMO for respiratory failure.

\begin{tabular}{|c|c|c|c|c|c|c|c|c|c|}
\hline Patients & Age/Gender & $\begin{array}{l}\text { SAPS II at } \\
\text { admission }\end{array}$ & Indication & $\begin{array}{c}\text { Time to ECMO } \\
\text { from ARDS } \\
\text { diagnosis (days) }\end{array}$ & $\begin{array}{l}\text { Hours of critical hypoxia } \\
(\mathrm{PaO2} / \mathrm{FiO2}<60) \text { and } / \text { or } \\
\text { critical acidosis } \\
(\mathrm{pH}<7.20)\end{array}$ & $\begin{array}{l}\text { ECMO duration } \\
\text { (hours) }\end{array}$ & $\begin{array}{l}\text { ECMO-related } \\
\text { complications }\end{array}$ & $\begin{array}{c}\text { ICU LOS } \\
\text { (days) }\end{array}$ & $\begin{array}{c}\text { ICU } \\
\text { outcome }\end{array}$ \\
\hline Pt 1 & 70/M & 27 & $\begin{array}{c}\text { ARDS } \\
\text { (infective) }\end{array}$ & 12 & 4 & 269 & Local bleeding & 33 & Survived \\
\hline Pt 2 & 19/M & 47 & $\begin{array}{c}\text { ARDS } \\
\text { (post-traumatic) }\end{array}$ & 1 & 4 & 33 & None & 3 & Non survived \\
\hline Pt 3 & $64 / F$ & 62 & $\begin{array}{c}\text { ARDS } \\
\text { (infective) }\end{array}$ & 1 & 2 & 44 & $\begin{array}{l}\text { Intracranial } \\
\text { bleeding }\end{array}$ & 3 & Non survived \\
\hline Pt 4 & $65 / M$ & 58 & $\begin{array}{c}\text { ARDS } \\
\text { (post-traumatic) }\end{array}$ & 1 & 1 & 231 & Local bleeding & 65 & Survived \\
\hline Pt 5 & $69 / M$ & 29 & $\begin{array}{c}\text { ARDS } \\
\text { (infective) }\end{array}$ & 1 & 5 & 264 & Local bleeding & 20 & Survived \\
\hline Pt 6 & $67 / M$ & 82 & $\begin{array}{c}\text { ARDS } \\
\text { (infective) }\end{array}$ & 10 & 8 & 253 & Local bleeding & 12 & Non survived \\
\hline Pt 7 & $59 / \mathrm{M}$ & 50 & $\begin{array}{c}\text { ARDS } \\
\text { (infective) }\end{array}$ & 4 & 8 & 626 & $\begin{array}{l}\text { Oxygenator } \\
\text { failure }\end{array}$ & 27 & $\begin{array}{c}\text { Non } \\
\text { survived }\end{array}$ \\
\hline Pt 8 & $61 / M$ & 62 & $\begin{array}{c}\text { ARDS } \\
\text { (infective) }\end{array}$ & 5 & 5 & 330 & None & 15 & $\begin{array}{c}\text { Non } \\
\text { survived }\end{array}$ \\
\hline Pt 9 & $15 / M$ & 66 & $\begin{array}{l}\text { ARDS } \\
\text { (H1N1) }\end{array}$ & 0 & 5 & 137 & None & 17 & Survived \\
\hline Pt 10 & $58 / \mathrm{M}$ & 24 & $\begin{array}{l}\text { ARDS } \\
\text { (H1N1) }\end{array}$ & 2 & 4 & 154 & None & 13 & Survived \\
\hline Pt 11 & $44 / F$ & 46 & $\begin{array}{c}\text { Viral acute } \\
\text { lung failure } \\
(\mathrm{H} 1 \mathrm{~N} 1)\end{array}$ & 2 & 5 & 374 & Local bleeding & 20 & Survived \\
\hline
\end{tabular}


Table 1: Patients treated with ECMO for respiratory failure. (Continued)

\begin{tabular}{ccccccccccc}
\hline Pt 12 & $48 / \mathrm{M}$ & 40 & $\begin{array}{c}\text { ARDS } \\
\text { (H1N1) }\end{array}$ & 1 & 6 & 184 & Survived \\
\hline Pt 13 & $30 / M$ & 44 & $\begin{array}{c}\text { Viral acute } \\
\text { lung failure } \\
\text { (H1N1) }\end{array}$ & 1 & 6 & 151 & Survived \\
\hline
\end{tabular}

Table 2: Patients treated with V-A ECLS for in-hospital cardiac arrest.

\begin{tabular}{|c|c|c|c|c|c|c|c|c|c|c|c|}
\hline Patients & Age/Gender & $\begin{array}{l}\text { SAPS II at } \\
\text { admission }\end{array}$ & $\begin{array}{c}\text { Diagnosis at } \\
\text { hospital } \\
\text { admission }\end{array}$ & $\begin{array}{c}\text { Cardiac arrest } \\
\text { etiology }\end{array}$ & $\begin{array}{c}\text { Initial rhythm } \\
\text { of cardiac } \\
\text { arrest }\end{array}$ & $\begin{array}{c}\text { ACLS } \\
\text { duration to } \\
\text { ECLS } \\
\text { (minutes) }\end{array}$ & $\begin{array}{c}\text { Return of } \\
\text { Spontaneous } \\
\text { Circulation } \\
\text { (ROSC) }\end{array}$ & $\begin{array}{l}\text { ECLS duration } \\
\text { (hours) }\end{array}$ & $\begin{array}{l}\text { ECLS-related } \\
\text { complications }\end{array}$ & $\begin{array}{c}\text { ICU LOS } \\
\text { (days) }\end{array}$ & ICU outcome \\
\hline Pt 1 & $66 / F$ & 60 & Septic shock & $\begin{array}{l}\text { Multi Organ } \\
\text { Dysfunction } \\
\text { Syndrome }\end{array}$ & Asystole & 60 & No & 6 & None & 2 & Non survived \\
\hline Pt 2 & $59 / \mathrm{M}$ & 69 & Cardiac arrest & $\begin{array}{l}\text { Bridge to } \\
\text { diagnosis }\end{array}$ & $\begin{array}{c}\text { Pulseless } \\
\text { electrical } \\
\text { activity }\end{array}$ & 90 & Yes & 25 & None & 2 & Non survived \\
\hline Pt 3 & $16 / \mathrm{M}$ & 40 & $\begin{array}{l}\text { Trauma with } \\
\text { brain injury }\end{array}$ & Trauma & $\begin{array}{c}\text { Pulseless } \\
\text { electrical } \\
\text { activity }\end{array}$ & 45 & No & 46 & None & 9 & Non survived \\
\hline Pt 4 & $23 / M$ & 80 & Trauma & $\begin{array}{l}\text { Hemorrhagic } \\
\text { shock }\end{array}$ & $\begin{array}{c}\text { Pulseless } \\
\text { electrical } \\
\text { activity }\end{array}$ & 55 & No & 3 & None & 1 & Non survived \\
\hline
\end{tabular}


Table 3: Patients treated with V-A ECLS in case of cardiogenic shock.

\begin{tabular}{|c|c|c|c|c|c|c|c|c|}
\hline Patients & Age/Gender & $\begin{array}{l}\text { SAPS II at } \\
\text { admission }\end{array}$ & $\begin{array}{c}\text { Cardiogenic } \\
\text { shock etiology }\end{array}$ & $\begin{array}{c}\text { Intra Aortic } \\
\text { Balloon Pump }\end{array}$ & $\begin{array}{l}\text { ECLS duration } \\
\text { (hours) }\end{array}$ & $\begin{array}{l}\text { ECLS-related } \\
\text { complications }\end{array}$ & $\begin{array}{c}\text { ICU LOS } \\
\text { (days) }\end{array}$ & ICU outcome \\
\hline Pt 1 & $43 / M$ & 61 & $\begin{array}{c}\text { Post cardiac } \\
\text { arrest heart } \\
\text { failure-ARDS in } \\
\text { near-drowning }\end{array}$ & Yes & 120 & None & 26 & Survived \\
\hline Pt 2 & $55 / F$ & 67 & $\begin{array}{c}\text { Multi Organ } \\
\text { Dysfunction } \\
\text { Syndrome }\end{array}$ & No & 72 & None & 5 & Non survived \\
\hline Pt 3 & $68 / M$ & 91 & $\begin{array}{l}\text { Multi Organ } \\
\text { Dysfunction } \\
\text { Syndrome }\end{array}$ & No & 24 & None & 2 & Non survived \\
\hline Pt 4 & $24 / F$ & 47 & $\begin{array}{l}\text { Post cardiac } \\
\text { arrest heart } \\
\text { failure }\end{array}$ & Yes & 189 & $\begin{array}{c}\text { Local } \\
\text { bleeding, } \\
\text { aneurysm }\end{array}$ & 14 & Survived \\
\hline
\end{tabular}

\section{V-A ECLS for cardiac arrest and cardiogenic shock}

Four victims of intra-hospital cardiac arrest received V-A ECLS for cardiac support (Table 2). Patients were 41 years old (median, IQR 21-61; male sex 75\%). The median duration of advanced cardiac life support manoeuvres before ECLS start was 58 minutes (IQR 53-68), and the median duration of ECLS was 16 hours (5-30). In two patients, the ECLS support started in the Emergency Room. All four patients died during their ICU stay (one patient after ECLS withdrawal).

Data of the four patients treated for cardiogenic shock are represented in Table 3. Median age was 49 years (IQR 3858, male sex 50\%). Among them, 2 patients survived and were discharged from ICU. In these patients, median duration of ECLS was 96 hours (IQR 60-137). Intraaortic balloon pump was necessary in all four patients. Survival rate was $50 \%$.

\section{Discussion}

From the experience here reported, we can state that, with a close cooperation between different specialists (intensivist, cardiologist, cardiac surgeon, nurse, perfusionist), an ECLS Service can be started over a relatively limited period of time, achieving a high level of efficiency. Our model of ECLS team has allowed us to start extracorporeal support in different hospital scenarios, such as ICU and Emergency Room. This feature of flexibility and adaptability of our ECMO system has made it particularly beneficial during the Influenza A pandemic, making this resource available also in peripheral hospitals.
The management of a patient on ECLS is still challenging in terms of utilization of resources and commitment of health personnel. Beyond the insertion procedure, a multidisciplinary team can better accomplish the tasks of daily management of the patient, as an intensivist, a cardiac surgeon and a perfusionist should repeatedly evaluate the circuit and the patient to guarantee a safe and uneventful treatment. Furthermore, every ECLS patient needs a dedicated nurse. With the assistance of these dedicated professionals, also in-hospital transportation can be safely carried out (i.e. to radiological suite). In our population $63 \%$ of patients received a CT scan during ECLS treatment, and no transport-related complications occurred. The most common complication was local bleeding, usually simple to manage. In this regard, the use of Bioline surface-heparinized circuits allowed a limited dose of heparin, and may have reduced the incidence of complications such as coagulation, complement activation, thrombus formation and the need for transfusions [17-19].

The survival rate of $62 \%$ of our patients treated with ECMO for respiratory failure is comparable to other published studies. In 2004, Hemmila and co-workers retrospectively reviewed 255 patients with ARDS treated with ECMO between 1989 and 2004, showing a 67\% of patients successfully weaned from ECMO and a hospital discharge of 52\% [20]. More recently, the CESAR (Conventional ventilation or ECMO for Severe Adult Respiratory Failure) trial has shown an increase of survival rate, without severe disability, 6 months after randomization 
in patients treated with ECMO in comparison to conventional ventilation (63\% vs $47 \%)$ [4].

From the first phase of implementation, our service was conceived to provide extracorporeal support even in peripheral institutions, therefore a dedicated ambulance was specifically prepared and all equipment arranged for transportation. In our opinion, this is a key feature for an effective ECMO service as inter-hospital transportation of patients with severe respiratory failure can be challenging due to the fact that limited possibilities of intervention are available and clinical deterioration may occur [21]. Therefore, several centres recommend the start of extracorporeal assistance before transfer [22,12]. In our out-of-hospital ECMO experience, one patient was safety transferred by ambulance from a distance of $400 \mathrm{Km}$. We report quite a short time to establish V-A ECLS in case of in-hospital cardiac arrest (58 min). Furthermore, there is a trend towards a progressive reduction of this interval over time. Despite this remarkable performance of our ECLS system in terms of speed of response, no patient receiving extracorporeal support for cardiac arrest survived. In a large series of patients on extracorporeal support for in hospital cardiac arrest, Jaski and coworkers reported a long term survival rate of $23 \%$ in witnessed events and no survival in non-witnessed arrest. At multivariate analysis cardiac arrest in the critical care unit was found to be the only independent variable predictive of outcome [23]. In another series of 40 in-hospital cardiac arrest victims, time before ECLS was 105 minutes, and 20\% survival rate was reported [24]. In our experience, the number of cardiac arrest patients with ECLS is so limited that comparison to published data is not feasible. Nevertheless, the reason for not responding to V-A ECLS treatment in our cases might be possibly related to the severity of previous clinical condition (2 traumas, 1 septic shock) and to the underling organ dysfunction.

\section{Conclusions}

ECMO and V-A ECLS might be considered a therapeutic option in patients with severe ARDS and/or with cardiac failure or cardiac arrest. In our experience, a well-timed start of ECMO in case of ARDS, prevents the progression of ventilator-induced lung injury and increases the chances of lung recovery. Also in case of cardiogenic shock, an extracorporeal technique seems a viable option and increases the possibility of early cardiac recovery avoiding neurological damages and multi-organ failure. To guarantee a safe treatment, the involvement of several properly trained physicians and nurses seems advisable.

\section{Key messages}

- An ECLS Service can be effectively organized in a Center were the needed competencies are available (intensivist, cardiologist, cardiac surgeon).

- When physicians and nurses are skilled in the technique, the Service can provide a safe transfer of critically ill patients from remote hospitals.

- ECMO should be considered in the initial phase of ARDS, when failure to ventilation strategy occurs. - The resource of ECMO has resulted to be particularly important in the event of cases of severe respiratory failure, as in the last pandemic of Influenza A.

\section{Appendix 1: First contact criteria to discuss the need of ECLS}

The parameter are referred to a condition of lung protective ventilation's (tidal volume: $4-6 \mathrm{ml} / \mathrm{Kg}$ of predicted body weight; plateau pressure $\leq 30 \mathrm{cmH}_{2} \mathrm{O}$; $\mathrm{PEEP}>$ lower inflection point of the curve pressure-volume). PEEP: positive end-expiratory pressure; $\mathrm{PaO}_{2}$ : arterial oxygen partial pressure; $\mathrm{FiO}_{2}$ : inspired oxygen fraction; RR: respiratory rate; $\mathrm{SaO}_{2}$ : peripheral oxygen saturation; $\mathrm{SvO}_{2}$ : central venous oxygen saturation.

Acute respiratory failure with 1 of the following condition:

1. $\mathrm{SaO}_{2}<85 \%$ for at least 1 hour

2. Oxygenation Index ${ }^{1}>25$ for at least 6 hours after ventilation's optimization

3. $\mathrm{PaO}_{2} / \mathrm{FiO}_{2}<100$ with PEEP $\geq 10 \mathrm{cmH}_{2} \mathrm{O}$ for at least 6 hours after ventilation's optimization

4. Hypercarbia with $\mathrm{pH}<7.25$

5. $\mathrm{SvO}_{2}<65 \%$ with hematocrit $>30$ and under vasoactive drugs infusion

${ }^{1}$ Mean airway pressure $\left(\mathrm{cmH}_{2} \mathrm{O}\right) * \mathrm{FiO}_{2} * 100 / \mathrm{PaO}_{2}$

\begin{abstract}
Abbreviations
ARDS: adult respiratory distress syndrome; ECLS: extracorporeal life support; ECMO: extracorporeal membrane oxygenation; ICU: intensive care unit; PEEP: positive end-expiratory pressure; SAPS: simplified acute physiology score; TEE: transesophageal echocardiography.
\end{abstract}

\section{Competing interests}

The authors declare that they have no competing interests.

\section{Authors' contributions}

AP (Adriano Peris), MB, GC, AP (Andrea Pasquini), GS, GFG organized the ECLS/ ECMO Service. MB (Manuela Bonizzoli), GC, AP, SB, PB, CL reviewed the literature. SB, GC, GZ, AP wrote the draft of article. SB collected data. MB (Massimo Bonacchi) performed all ECLS/ECMO insertion procedures. $C L$ and $P B$ performed TEE assistance. AP (Adriano Peris), MB, GC, AP (Andrea Pasquini), MC, SB and EM managed cases here reported. All Authors have seen and approved the final revised version.

Acknowledgements

This paper was supported by institutional funds. 


\section{Author Details}

'Anaesthesia and Intensive Care Unit of Emergency Department, Careggi Teaching Hospital, Florence, Italy, 2Postgraduate School of Anesthesia and Intensive Care, Faculty of Medicine, University of Florence, Italy, ${ }^{3}$ Cardiac Surgery, Heart and Vessel Department, Careggi Teaching Hospital, Florence, Italy and ${ }^{4}$ ntensive Cardiac Coronary Unit, Heart and Vessel Department, Careggi Teaching Hospital, Florence, Italy

Received: 14 January 2010 Accepted: 21 May 2010

Published: 21 May 2010

\section{References}

1. Von Frey MGM: Studies on metabolism of isolated organs. A respirationapparatus for isolated organs. 1885.

2. Gibbon J: Artificial maintenance of circulation during experimental occlusion of pulmonary artery. Arch Surg 1937, 34:1 105-1131.

3. Schuerer DJ, Kolovos NS, Boyd KV, Coopersmith CM: Extracorporeal membrane oxygenation: current clinical practice, coding, and reimbursement. Chest 2008, 134:179-184

4. Peek GJ, Mugford M, Tiruvoipati R, Wilson A, Allen E, Thalanany MM, Hibbert CL, Truesdale A, Clemens F, Cooper N, Firmin RK, Elbourne D: Efficacy and economic assessment of conventional ventilatory support versus extracorporeal membrane oxygenation for severe adult respiratory failure (CESAR): a multicentre randomised controlled trial. Lancet 2009, 374:1351-1363.

5. Twigg S, Gibbon GJ, Perris T: The use of extracorporeal carbon dioxide removal in the management of life-threatening bronchospasm due to influenza infection. Anaesth Intensive Care 2008, 36:579-581.

6. Elliot SC, Paramasivam K, Oram J, Bodenham AR, Howell SJ, Mallick A: Pumpless extracorporeal carbon dioxide removal for life-threatening asthma. Crit Care Med 2007, 35:945-948.

7. Fischer S, Hoeper MM, Bein T, Simon AR, Gottlieb J, Wisser W, Frey L, Van Raemdonck D, Welte T, Haverich A, Strueber M: Interventional lung assist: a new concept of protective ventilation in bridge to lung transplantation. Asaio J 2008, 54:3-10

8. Fischer S, Hoeper MM, Tomaszek S, Simon A, Gottlieb J, Welte T, Haverich A, Strueber M: Bridge to lung transplantation with the extracorporeal membrane ventilator Novalung in the veno-venous mode: the initial Hannover experience. Asaio J 2007, 53:168-170.

9. Conrad SA, Rycus PT, Dalton H: Extracorporeal Life Support Registry Report 2004. Asaio J 2005, 51:4-10.

10. Chen YS, Lin JW, Yu HY, Ko WJ, Jerng JS, Chang WT, Chen WJ, Huang SC, Chi NH, Wang CH, Chen LC, Tsai PR, Wang SS, Hwang JJ, Lin FY: Cardiopulmonary resuscitation with assisted extracorporeal lifesupport versus conventional cardiopulmonary resuscitation in adults with in-hospital cardiac arrest: an observational study and propensity analysis. Lancet 2008, 372:554-561.

11. Ventilation with lower tidal volumes as compared with traditional tidal volumes for acute lung injury and the acute respiratory distress syndrome. The Acute Respiratory Distress Syndrome Network. NEng/ J Med 2000, 342:1301-1308.

12. Zimmermann M, Bein T, Philipp A, Ittner K, Foltan M, Drescher J, Weber F, Schmid FX: Interhospital transportation of patients with severe lung failure on pumpless extracorporeal lung assist. Br J Anaesth 2006, 96:63-66.

13. Valente Barbas CS: Lung recruitment maneuvers in acute respiratory distress syndrome and facilitating resolution. Crit Care Med 2003, 31:S265-271.

14. Adhikari NK, Burns KE, Friedrich JO, Granton JT, Cook DJ, Meade MO: Effect of nitric oxide on oxygenation and mortality in acute lung injury: systematic review and meta-analysis. Bmj 2007, 334:779.

15. Pagani FD, Aaronson KD, Dyke DB, Wright S, Swaniker F, Bartlett RH: Assessment of an extracorporeal life support to LVAD bridge to heart transplant strategy. Ann Thorac Surg 2000, 70:1977-1984. discussion 1984-1975

16. Polderman $\mathrm{KH}$ : Hypothermia and neurological outcome after cardiac arrest: state of the art. Eur J Anaesthesiol Suppl 2008, 42:23-30.

17. Palatianos GM, Foroulis CN, Vassili MI, Astras G, Triantafillou K, Papadakis E, Lidoriki AA, lliopoulou E, Melissari EN: A prospective, double-blind study on the efficacy of the bioline surface-heparinized extracorporeal perfusion circuit. Ann Thorac Surg 2003, 76:129-135.
18. Wendel HP, Philipp A, Weber N, Birnbaum DE, Ziemer G: Oxygenator thrombosis: worst case after development of an abnormal pressure gradient--incidence and pathway. Perfusion 2001, 16:271-278.

19. Wimmer-Greinecker G, Matheis G, Martens S, Oremek G, Abdel-Rahman U, Moritz A: Synthetic protein treated versus heparin coated cardiopulmonary bypass surfaces: similar clinical results and minor biochemical differences. Eur J Cardiothorac Surg 1999, 16:211-217.

20. Hemmila MR, Rowe SA, Boules TN, Miskulin J, McGillicuddy JW, Schuerer DJ, Haft JW, Swaniker F, Arbabi S, Hirschl RB, Bartlett RH: Extracorporeal life support for severe acute respiratory distress syndrome in adults. Ann Surg 2004, 240:595-605. discussion 605-597

21. Gebremichael M, Borg U, Habashi NM, Cottingham C, Cunsolo L, McCunn $\mathrm{M}$, Reynolds HN: Interhospital transport of the extremely ill patient: the mobile intensive care unit. Crit Care Med 2000, 28:79-85.

22. Linden V, Palmer K, Reinhard J, Westman R, Ehren H, Granholm T, Frenckner B: Inter-hospital transportation of patients with severe acute respiratory failure on extracorporeal membrane oxygenation--national and international experience. Intensive Care Med 2001, 27:1643-1648.

23. Jaski BE, Ortiz B, Alla KR, Smith SC, Glaser D Jr, Walsh C, Chillcott S, Stahovich M, Adamson R, Dembitsky W: A 20-year experience with urgent percutaneous cardiopulmonary bypass for salvage of potential survivors of refractory cardiovascular collapse. J Thorac Cardiovasc Surg 139:753-757. e751-752

24. Massetti M, Tasle M, Le Page O, Deredec R, Babatasi G, Buklas D, Thuaudet S, Charbonneau P, Hamon M, Grollier G, Gerard JL, Khayat A: Back from irreversibility: extracorporeal life support for prolonged cardiac arrest. Ann Thorac Surg 2005, 79:178-183. discussion 183-174

doi: $10.1186 / 1757-7241-18-28$

Cite this article as: Peris et al., Extracorporeal life support for management of refractory cardiac or respiratory failure: initial experience in a tertiary centre Scandinavian Journal of Trauma, Resuscitation and Emergency Medicine 2010, 18:28

\section{Submit your next manuscript to BioMed Central and take full advantage of:}

- Convenient online submission

- Thorough peer review

- No space constraints or color figure charges

- Immediate publication on acceptance

- Inclusion in PubMed, CAS, Scopus and Google Scholar

- Research which is freely available for redistribution
C) Biomed Central 